\title{
Transient ionization of the mesosphere during auroral breakup: Arase satellite and ground-based conjugate observations at Syowa Station
}

\author{
Ryuho Kataoka ${ }^{1,11^{*}}$ (D), Takanori Nishiyama ${ }^{1,11}$, Yoshimasa Tanaka 1,2,11, Akira Kadokura 1,2,11, \\ Herbert Akihito Uchida ${ }^{1,11}$, Yusuke Ebihara ${ }^{3}$, Mitsumu K. Ejiri ${ }^{1,11}$, Yoshihiro Tomikawa ${ }^{1,11}$, Masaki Tsutsumi ${ }^{1,11}$, \\ Kaoru Sato ${ }^{4}$, Yoshizumi Miyoshi ${ }^{5}$, Kazuo Shiokawa ${ }^{5}{ }^{\circ}$, Satoshi Kurita ${ }^{5}$, Yoshiya Kasahara ${ }^{6}$, Mitsunori Ozaki $^{6}$, \\ Keisuke Hosokawa ${ }^{7}$, Shoya Matsuda ${ }^{8}$, Iku Shinohara ${ }^{8}$, Takeshi Takashima ${ }^{8}$, Tatsuhiko Sato ${ }^{9}$, Takefumi Mitani ${ }^{8}$, \\ Tomoaki Hori ${ }^{5}$ and Nana Higashio ${ }^{10}$
}

\begin{abstract}
Transient mesospheric echo in the VHF range was detected at an altitude of 65-70 km during the auroral breakup that occurred from 2220 to 2226 UT on June 30, 2017. During this event, the footprint of the Arase satellite was located within the field of view of the all-sky imagers at Syowa Station in the Antarctic. Auroral observations at Syowa Station revealed the dominant precipitation of relatively soft electrons during the auroral breakup. A corresponding spike in cosmic noise absorption was also observed at Syowa Station, while the Arase satellite observed a flux enhancement of $>100 \mathrm{keV}$ electrons and a broadband noise without detecting chorus waves or electromagnetic ion cyclotron waves. A general-purpose Monte Carlo particle transport simulation code was used to quantitatively evaluate the ionization in the middle atmosphere. Results of this study indicate that the precipitation of energetic electrons of $>100 \mathrm{keV}$, rather than X-rays from the auroral electrons, played a dominant role in the transient and deep $(65-70 \mathrm{~km})$ mesospheric ionization during the observed auroral breakup.
\end{abstract}

Keywords: Aurora, Mesosphere, X-rays, Energetic electrons

\section{Introduction}

Significant ionization of the mesosphere has long been documented during substorms. One of the most prominent phenomena is found near the onset and is referred to as "absorption spikes," which are observed by groundbased riometers (Parthasarathy and Berkey 1965; Nielsen and Axford 1977). The absorption spike events are found in a vast majority of substorms (Hargreaves et al. 1997; Aminaei et al. 2006; Spanswick et al. 2006) and are often associated with energetic electron bursts in the inner

\footnotetext{
*Correspondence: kataoka.ryuho@nipr.ac.jp

${ }^{1}$ National Institute of Polar Research, 10-3 Midori-cho, Tachikawa, Tokyo 190-8518, Japan

Full list of author information is available at the end of the article
}

magnetosphere (Baker et al. 1981; Kremser et al. 1982; 1988). In pulsating auroras, the mesospheric ionization is due to the precipitation of energetic electrons of a few hundred keV (Brown et al. 1976; Sandahl et al. 1980; Miyoshi et al. 2015; Oyama et al. 2017). Atmospheric ionization that results from this energetic particle precipitation in the mesosphere and lower thermosphere plays an essential role in linking the space and terrestrial environments via the generation of odd nitrogen and odd hydrogen (Codrescu et al. 1997; Daae et al. 2012; Isono et al. 2014; Seppala et al. 2015; Tomikawa 2017), and, thus, it is important to quantitatively evaluate the fundamental factors that lead to such deep ionization scenarios to understand its mechanisms and characteristics better. 
In 2017, the Arase satellite began full in situ observation of energetic particles and electromagnetic waves in the inner magnetosphere in an effort to understand the dynamics of radiation belts and the inner magnetosphere better (Miyoshi et al. 2018). The energetic particles precipitating from the inner magnetosphere deposit their energy in the atmosphere, and this is improving our understanding of the associated atmospheric response, which has also been an important objective of the Arase satellite project.

The Program of the Antarctic Syowa Mesosphere Stratosphere Troposphere Incoherent Scatter Radar (PANSY) at Syowa Station, in the Antarctic $\left(-69.00^{\circ} \mathrm{S}, 39.58^{\circ} \mathrm{E}\right.$; $-70.46^{\circ}$ magnetic latitude) has been in operation continuously since September 2015 at an observation frequency of $47 \mathrm{MHz}$ (Sato et al. 2014). It is accompanied by a suite of important ground-based instruments, including a high-speed auroral imager, a meridian scanning photometer, and imaging riometer. The PANSY radar system detects polar mesosphere winter echoes, which are caused by neutral turbulence in the weakly ionized atmosphere at an altitude of 55-85 km (Czechowsky et al. 1989; Brattli et al. 2006; Lübken et al. 2007). Recent observations revealed that the sudden intensification of mesospheric echoes around $65 \mathrm{~km}$ was caused by electron density enhancements in the D region during a solar proton event (Nishiyama et al. 2018), implying that intensified mesospheric echoes may serve as a proxy of electron density variations at mesospheric altitudes.

There have been several occasions when the ionospheric footprint of the Arase satellite has passed through the field of view of the all-sky auroral imagers in operation at Syowa Station. As expected, the Arase satellite, PANSY radar, and other ground-based conjugate instruments simultaneously observed an isolated substorm at Syowa Station on June 30, 2017. The purpose of this study is to report on a rare comprehensive data set from these cutting-edge conjugate observation instruments and discuss the transient mesospheric ionization associated with auroral breakup, combined with a general-purpose Monte Carlo particle transport simulation code particle and heavy ion transport code system (PHITS). In this study, the EGS5 mode (Hirayama et al. 2005) in PHITS version 3.02 (Sato et al. 2018) was employed.

\section{Results}

Figure 1 shows the data from the meridian scanning photometer at Syowa Station for the 2-h time interval from 2200 to 2400 UT on June 30, 2017. Soft electrons of a few $\mathrm{keV}$ dominantly precipitated during the auroral breakup from 2220 to 2226 UT, which was identified from the relatively high auroral intensity of $845 \mathrm{~nm}$ compared to 670 nm (Ono 1993; Ono and Morishima 1994). After
2230 UT, the overall auroras became diffuse and began pulsating, and the characteristic energy of the electrons increased, which was also identified from the 845/670 ratio. High-speed auroral imagers clearly captured the rapid complex motion of the bright discrete auroras with a tall curtain-like shape at the auroral breakup until 2226 UT, and faint pulsating auroras were observed thereafter (Additional file 1: Movie A1).

Figure 2 shows the backscattered echo power over time and height sections for the 2-h time interval from 2200 to 2400 UT on June 30, 2017, based on the PANSY radar observations. Atmospheric ionization can be sensitively detected based on the relative intensification of echo power, although a quantitative estimation of the ionization rate or electron density from the echo power itself is rather difficult. As expected, a layer at an altitude of $\sim 80 \mathrm{~km}$ was ionized during the post-breakup pulsating aurora activity from 2230 to 2330 UT. The ionization source can be attributed to the precipitating electrons of $>10 \mathrm{keV}$ (see Miyoshi et al. 2015), which is also supported by the relatively low 845/670 ratio depicted in Fig. 1 . The echo altitude gradually descended, which was likely due to the downward propagation of the neutral turbulence at that time. It is also important to note that intermittent and transient echoes above $80 \mathrm{~km}$ during the 2-h interval, which did not coincide in five beam directions, were largely caused by meteors (Nishiyama et al. 2015).

Interestingly, the echo was also enhanced at an altitude of $65-70 \mathrm{~km}$ as the auroral breakup began from 2220 to 2226 UT, regardless of the dominant presence of lowenergy auroral electrons. It is not possible to rule out the possible role of the direct injection of $>100 \mathrm{keV}$ energetic electrons, even if the auroral electrons were predominantly soft, because the flux of such energetic electrons would be significantly lower than the auroral electrons, and their impact on the auroral emission is negligible.

More specifically, the echo enhancements at altitudes $<70 \mathrm{~km}$ were confirmed at only two successive time intervals, specifically 22:21:26-22:22:47 UT and 22:24:4422:26:05 UT. In the next time frame of 22:28:02-22:29:23 $\mathrm{UT}$, the echo enhancement disappeared at altitudes $<70 \mathrm{~km}$. The signals were clearer at the zenith, and in south/east beams (i.e., poleward beams) compared with those associated with the north/west beams, where auroral emission is also intensified, which was observed in all-sky images (Additional file 1: Movie A1). The altitude range of the transient echo enhancement was found to be broader than the narrow echo band noted during the pulsating auroras.

The imaging riometer at Syowa Station observed cosmic noise absorption during the auroral breakup, thus providing additional evidence to support the PANSY radar observations associated with the mesospheric 


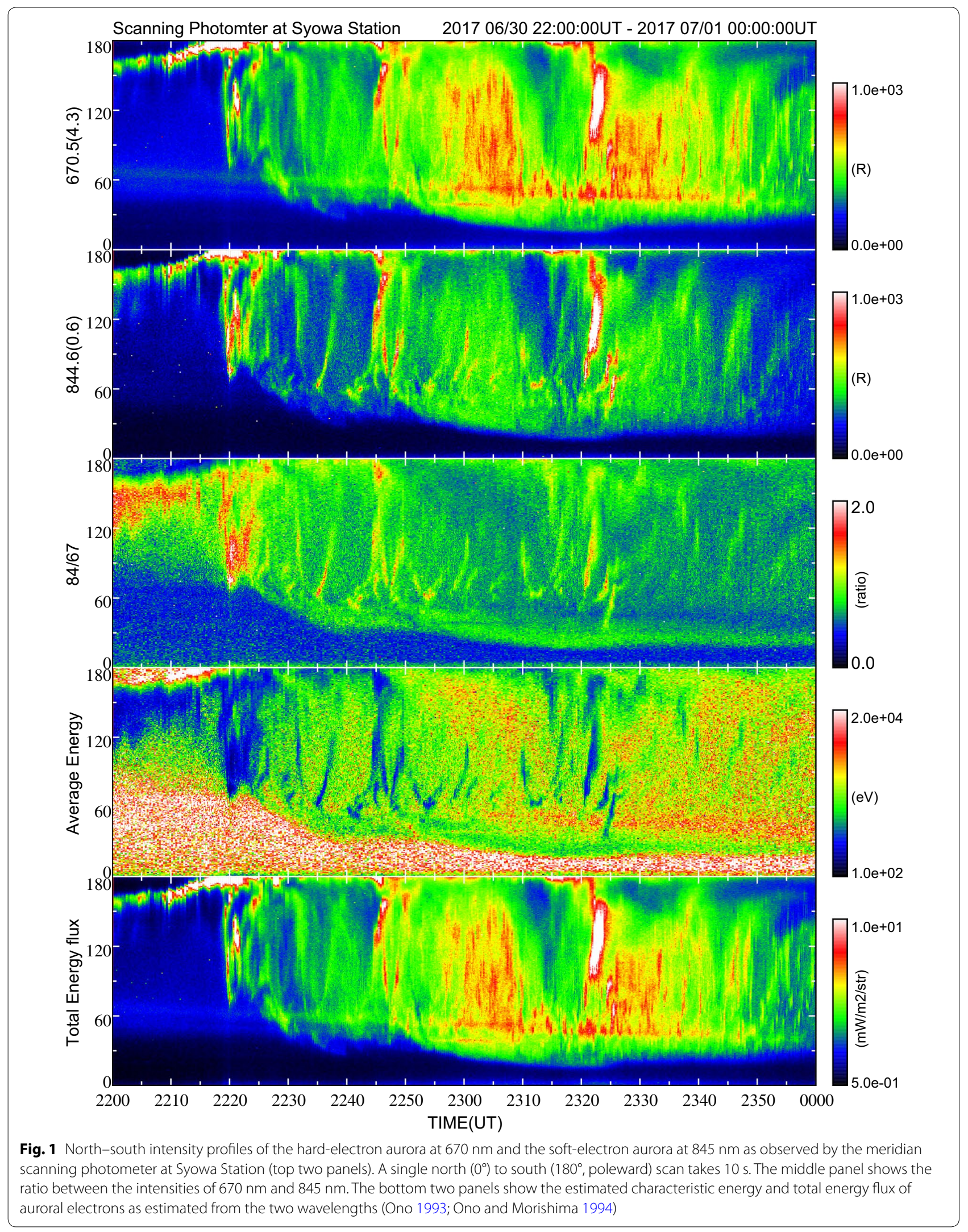




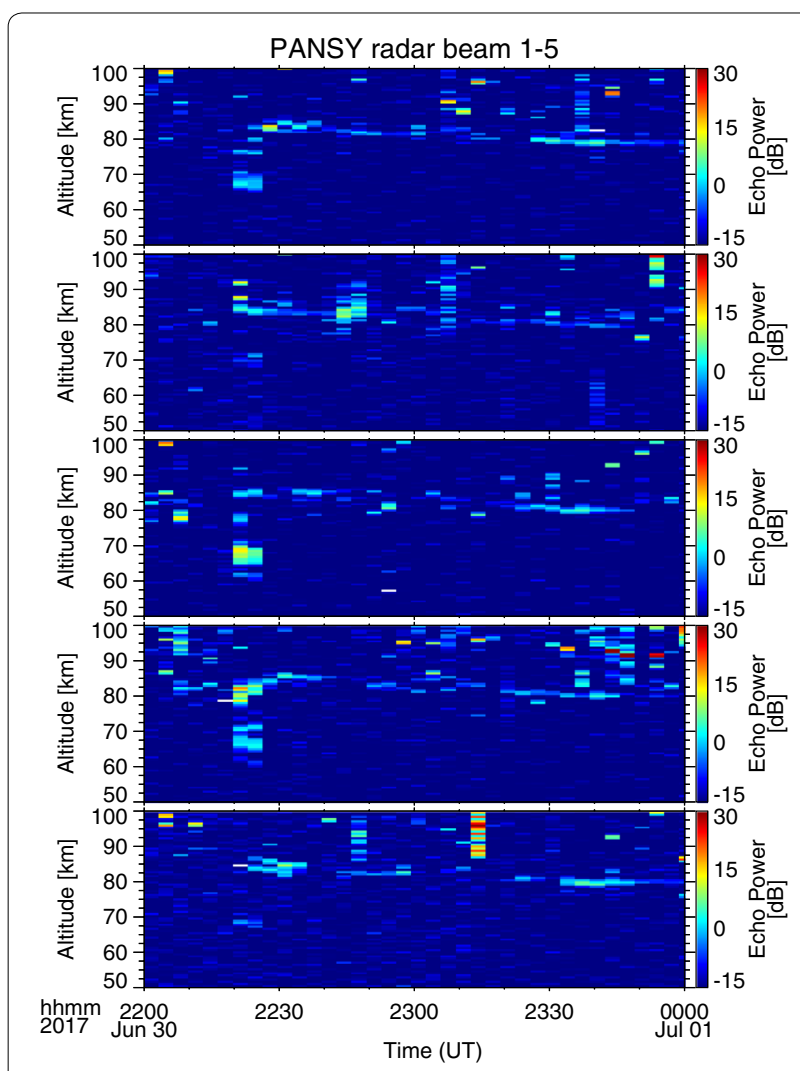

Fig. 2 Altitude profiles of the echo power enhancement as observed by the PANSY radar, Syowa Station. From top to bottom, the directions of the five beams are the zenith, north, east, south, and west, respectively, at a zenith angle of $10^{\circ}$. The beam width is $\sim 1^{\circ}$. The altitude range resolution is $0.6 \mathrm{~km}$, and the temporal resolution is $\sim 4$ min

ionization (Fig. 3). Relatively weak ionizations were also detected during the 1.5 -h time period of pulsating auroras. The bottom two panels of Fig. 3 show the in situ observation of energetic particles made by the highenergy electron experiments (HEP) (Mitani et al. 2018) and extremely high-energy electron experiment (XEP) (Higashio et al. 2018) onboard the Arase satellite. There is a clear signature of rapid flux enhancement of several hundred keV electrons observed by the HEP and XEP instruments that match the timing of the spike identified in the riometer data. Therefore, the flux enhancement of energetic electrons is likely to be one of major causes of the transient mesospheric ionization if these electrons precipitate into the atmosphere. The possibility of the flux enhancement of energetic electrons is quantitatively discussed later in this paper.

Figure 4 presents the in situ observations of the plasma waves detected by the high-frequency analyzer (HFA) and onboard frequency analyzer (OFA) of the plasma wave experiment (PWE) onboard the Arase satellite (Kasaba et al. 2017; Kasahara et al. 2018; Kumamoto et al. 2018; Matsuda et al. 2018; Ozaki et al. 2018) for the same 2-h time interval from 2200 to 2400 UT on June 30, 2017. The yellow and magenta lines represent the electron-gyro frequency and half-gyro frequency, respectively. For the 2-h period, the footprint of the Arase satellite passed through the eastern side of the field of view of the all-sky cameras from low latitude to high latitude. It is important to note that possible errors associated with the footprint mapping by the IGRF model can be as much as a few degrees, as evaluated from the T96 (Tsyganenko 1996) and T04s (Tsyganenko and Sitnov 2005) models during this event (Additional file 2: Figure A1).

Broadband noise was observed during the auroral breakup from $\sim 2220$ to 2230 UT, while continuum emissions from the plasmapause were observed during the pulsating auroras from $\sim 2230$ to 2400 UT. Note that the Arase satellite traversed across the plasmapause at $L=6.6$ at $\sim 2150$ UT, which was also detected by HFA (not shown), implying that this event was observed just outside the plasmapause. The Arase satellite did not observe electromagnetic ion cyclotron waves nor chorus waves during the 2-h event.

\section{Discussions}

The mesospheric ionization is quantitatively evaluated using PHITS (Sato et al. 2018). The following hypothesis is proposed as an explanation for the transient ionization of the mesosphere. Note that X-rays are emitted from the soft auroral electrons of $<10 \mathrm{keV}$ by bremsstrahlung emission at an altitude of $\sim 100 \mathrm{~km}$, and these X-rays can penetrate deep into the mesosphere and deposit their energy. Altitude profiles of the local auroral energy deposition due to electrons and X-rays can be calculated by well-established methods (Rees 1964; Berger and Seltzer 1972; Luhmann 1977). In this paper, we use PHITS (Sato et al. 2018) to simulate three ionization models, including the auroral breakup model A (soft electrons and high flux), the pulsating aurora model B (hard electrons and low flux), and the energetic electron model C. In this study, the MSISE-90 model (Hedin 1991) was employed for simulating the neutral atmosphere over Syowa Station at 2200 UT on June 30, 2017.

The ratio of $845 / 670$, apparent tall curtain shape, rapid motion, and timing near the substorm onset led to the assumption of relatively broadband electron spectra, which is represented by the wave aurora (Mende et al. 2003) or broadband electrons often associated with broadband noise (Newell et al. 2009). Therefore, for model A, we assumed a Gaussian energy spectrum with characteristic energy $E_{\mathrm{c}}$ of $2.5 \mathrm{keV}$ (Strickland et al. 1993) and a relatively 

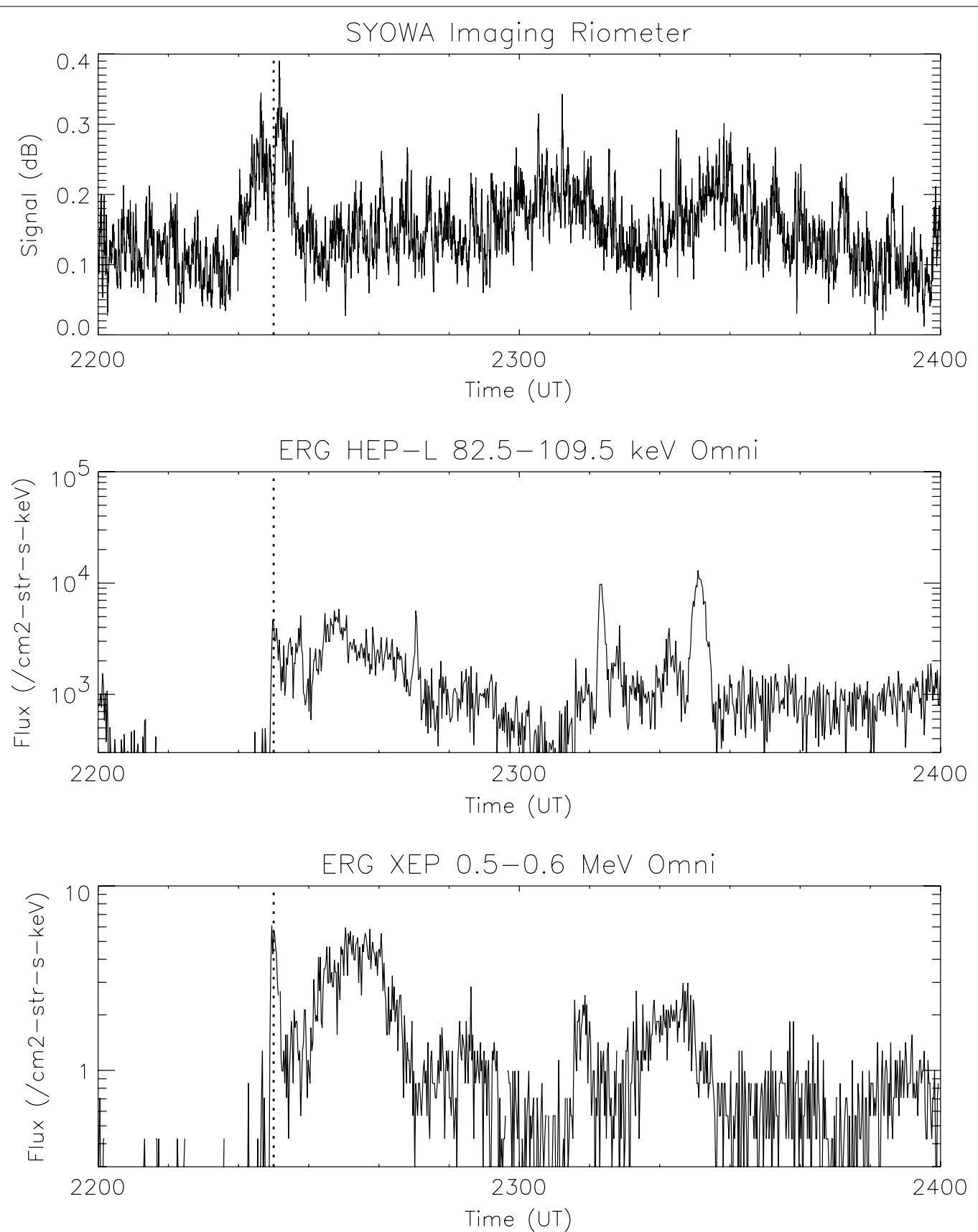

Fig. 3 Cosmic noise absorption event at 2225 UT on June 30, 2017, as observed by the imaging riometer at Syowa Station. The observation frequency was $38.2 \mathrm{MHz}$. The beam direction is toward the zenith and the beam width is approximately $10^{\circ}$. The data are running averaged by an 8-s window to reduce random noise. The bottom panels show the omnidirectional flux of 82.5-109.5 keV and 0.5-0.6 MeV electrons, as observed by the HEP and XEP instrument of the Arase satellite, respectively

wide Gaussian width $W$ of $0.75 E_{c}$. The pitch-angle distribution was assumed to be a beam with a $30^{\circ}$ width from the center, where the differential flux can be expressed by Eq. (1).

$$
f_{\text {discrete }}(E)=\frac{Q}{\pi^{3 / 2} W E_{\mathrm{c}}} \exp \left(-\left(\frac{E-E_{\mathrm{c}}}{W}\right)^{2}\right),
$$

where $Q$ denotes the total energy flux.

On the other hand, pulsating auroras typically have a harder spectrum, which is also supported by the $845 / 670$ ratio (Fig. 2). For model B, an energy spectrum of a kappa distribution (Frahm et al. 1997) was assumed with a peak 

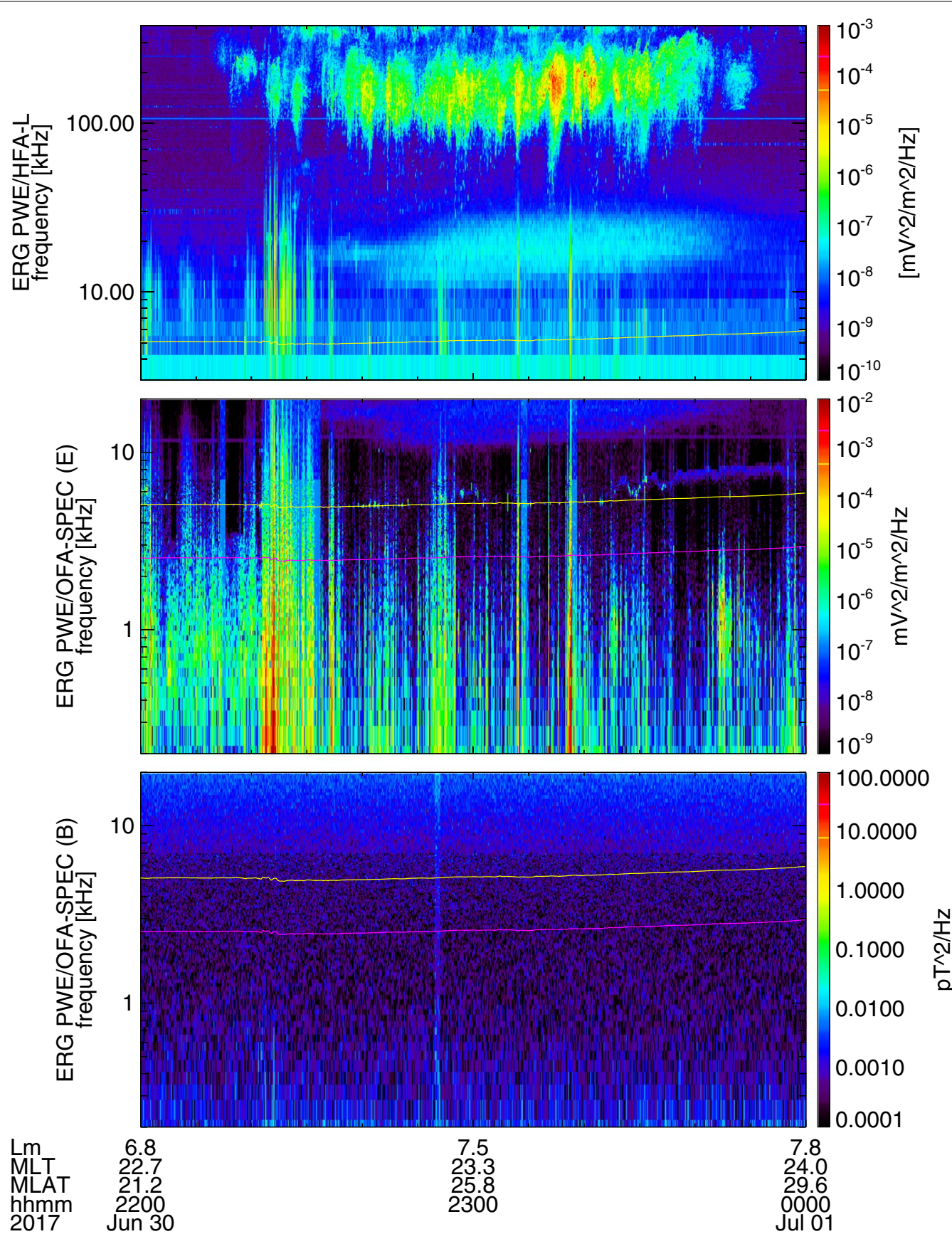

Fig. 4 Electromagnetic wave activity in the magnetosphere as observed by the Arase satellite for the 2-h time interval from 2200 to 2400 UT on June 30, 2017, when the footprint passed through the field of view of the all-sky cameras at Syowa Station

energy $E_{\mathrm{p}}$ of $1 \mathrm{keV}$ and a kappa parameter $\kappa=8$, considering a high-energy tail in addition to Maxwell distribution (Strickland et al. 1993). The pitch angle distribution was assumed to be isotropic in the downward hemisphere, and the differential flux can be expressed by Eq. (2).

$$
f_{\text {diffuse }}(E)=\frac{Q}{2 \pi E_{\mathrm{p}}^{3}} E\left(1+\left(\frac{E}{\kappa E_{\mathrm{p}}}\right)^{-\kappa-1}\right)
$$



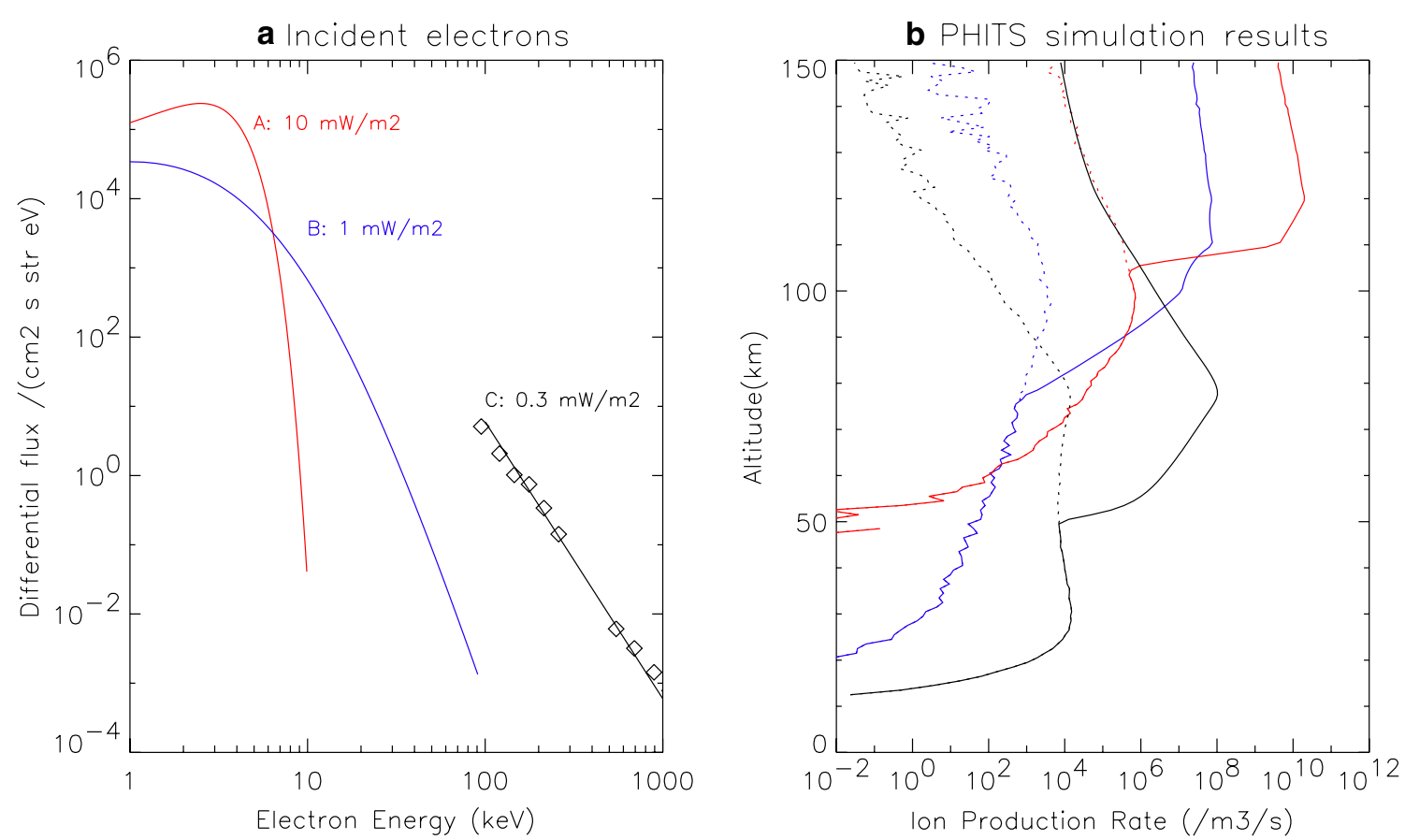

Fig. 5 Incident electron energy spectra (left) and their ion production rate in the atmosphere (right) over Syowa Station obtained from the PHITS simulation. The red lines represent broadband electrons associated with discrete auroras in model $\mathrm{A}$, the blue lines represent the diffuse pulsating auroras in model B, and the black lines represent the energetic electrons in model C. Peak HEP and XEP omnidirectional flux values are depicted by diamonds. The contributions of $X$-rays are shown by dotted lines

Figure 5 shows the results obtained from PHITS simulation for models $\mathrm{A}$ and $\mathrm{B}$. The ionization levels for a typical total energy flux of $1 \mathrm{~mW} \mathrm{~m}{ }^{-2}$ are shown for model B, and those for $10 \mathrm{~mW} \mathrm{~m}{ }^{-2}$ are shown for model A. Direct ionization by electrons with $\sim 100 \mathrm{keV}$ energy can be seen at $80 \mathrm{~km}$ altitude for model $\mathrm{B}$. Note that X-ray ionization of model A is comparable to or even higher than electron ionization of model B at an altitude of $65-80 \mathrm{~km}$. As a useful reference, some other simulation results are also presented in the Additional file 3 (Figure A2) with different parameters.

Then, the resultant riometer response was calculated to quantitatively test the above hypothesis. We calculated the cosmic noise absorption by the formulation of $4.6 \times 10^{-5} v \omega^{-2} q^{0.5} a^{-0.5} \mathrm{~dB} \mathrm{~m}^{-1}$, where $q$ is the ion pair production rate. The recombination coefficient $a$ was obtained from Gledhill (1986), and the collision frequency $v$ was obtained from Aggarwal et al. (1979). The observation frequency $\omega$ of the riometer was $38.2 \mathrm{MHz}$. The height integrated intensities of cosmic noise absorption were estimated to be only $0.016 \mathrm{~dB}$ and $0.005 \mathrm{~dB}$ for models A and B, respectively, which are an order of magnitude smaller than the observed values, as shown in Fig. 3. From the above results, we expect an order of magnitude larger ionization than those of the soft and hard auroral electrons to take place in the mesosphere during the event investigated in this study.

Here we introduce model $\mathrm{C}$ to evaluate the possible role of precipitating energetic electrons. The differential flux of the power law distribution can be expressed using Eq. (3),

$$
f_{\text {burst }}(E)=\frac{Q}{2 \pi}(\gamma-2) E_{0}^{\gamma-2} E^{-\gamma}
$$

where $Q$ denotes the approximate downward total energy flux. For simplicity, we assumed a lower energy cutoff $E_{0}$ of $100 \mathrm{keV}$, and set the maximum energy cutoff at $1000 \mathrm{keV}$. To roughly fit the omnidirectional electron flux of HEP and XEP, the possible maximum total energy flux $Q$ of $0.3 \mathrm{~mW} \mathrm{~m}{ }^{-2}$ was assumed for three different power law indices $\gamma$ of 3.5, 4.0, and 4.5.

The result of the PHITS simulation for model $\mathrm{C}$ is represented by the black lines in Fig. 5b. Comparing model $\mathrm{C}$ to models $\mathrm{A}$ and $\mathrm{B}$, ionization that was $2-3$ orders of magnitude larger was obtained at an altitude of $50-80 \mathrm{~km}$. The integrated cosmic noise absorption intensity of model $\mathrm{C}$ was $0.053 \mathrm{~dB}$, which represents a more reasonable value to explain the riometer observations. Additional contributions from the omitted populations of less energetic electrons $<100 \mathrm{keV}$, which cannot 
reach to a $65 \mathrm{~km}$ altitude, can fill the gap of simulated and observed cosmic noise absorption intensities. Based on the above PHITS simulations, we concluded that the precipitation of energetic electrons of $>100 \mathrm{keV}$, rather than $\mathrm{X}$-rays from the auroral electrons, played a dominant role in the transient and deep mesospheric ionization during the auroral breakup.

The possible cause of the precipitation of energetic electrons is discussed as follows. The possible pitch angle scattering of energetic electrons $>100 \mathrm{keV}$ from the inner magnetosphere is generally attributed to either electromagnetic ion cyclotron waves or chorus waves (e.g., Miyoshi et al. 2008, 2015). However, the Arase satellite did not observe electromagnetic ion cyclotron waves or chorus waves. In general, electromagnetic ion cyclotron waves should be found in the equatorial region. By contrast, the resonance energy of chorus waves depends on the off-equatorial magnetic latitude in the magnetosphere, and even $\mathrm{MeV}$ electrons can precipitate into the atmosphere when the chorus waves propagate at higher latitudes (Horne and Thorne 2003; Miyoshi et al. 2015). It is also possible that during this particular event the Arase satellite was not in the correct position to observe the chorus wave activity. Meredith et al. (2012) conducted a statistical survey of chorus waves using multiple satellites and found that between magnetic latitudes of $15^{\circ}-30^{\circ}$ on the nightside, chorus intensities drop off significantly compared to those in the equatorial region. Chorus waves that reach higher latitudes were found to be restricted to dayside. Thus, it is possible that the Arase satellite was outside of the region where one would expect to see the chorus waves or electromagnetic ion cyclotron waves.

Finally, we briefly discuss the transient timescale of the appearance and disappearance of the echo, as shown in Fig. 2. Note that both the horizontal and vertical appearance and disappearance of radar echoes in the wintertime mesosphere have been known to depend on a complex interplay of both ionizing sources and possibly turbulence, in addition to nonionizing radiation, such as daylight, ion-chemistry and the charging behavior of dust or smoke layers (Kirkwood 2007; Lübken et al. 2006; Kirkwood et al. 2015; Nishiyama et al. 2018). It is important to note that during the present spike event the deep ionization disappeared rather quickly. At a nighttime altitude of $65 \mathrm{~km}$, the recombination rate was $10^{-9} \mathrm{~m}^{3} \mathrm{~s}^{-1}$ (Friedrich et al. 2004), and the electron density from the results of model $\mathrm{C}$ was on the order of $10^{7} \mathrm{~m}^{-3}$. Therefore, the timescale is $\sim 10^{2} \mathrm{~s}$, which is consistent with the spike appearance. However, the estimated electron density at $65 \mathrm{~km}$ was not large enough by itself to generate detectable mesospheric echoes (Lübken et al. 2006; Nishiyama et al. 2018). Therefore, the observed transient echo seems to have been caused by ionization due to electron precipitations and strong neutral turbulence and/or meteor smoke particles. Unfortunately, we have no mesospheric wind information during this period, and a vertical wind profile behind the echo layer cannot be examined. Ion-chemistry, including charging behavior of meteor smoke particles, also plays an important role in forming mesospheric echo layers in the VHF range. Electron density variations related to dust and smoke particles, especially during geomagnetically disturbed periods, should be taken into account in future research efforts.

\section{Conclusions}

The transient mesospheric ionization was identified at an altitude of around $65-70 \mathrm{~km}$ over Syowa Station during the auroral breakup that occurred from 2220 to 2226 UT on June 30, 2017, when the footprint of the Arase satellite was located close to Syowa Station. Instruments onboard the Arase satellite observed the rapid flux enhancement of several hundred $\mathrm{keV}$ electrons at the same time. Such energetic electrons, which represent a different population from auroral electrons, precipitated to transiently ionize the deep mesosphere during the auroral breakup.

\section{Additional files}

\begin{abstract}
Additional file 1: Movie A1. Panchromatic all-sky images obtained from the Electron-Multiplying Charge Coupled Device (EMCCD) camera at Syowa Station. Magnetic north is at the top, and magnetic east is to the right. The original sampling rate was 100 frames $s^{-1}$, and all the images were averaged every $0.1 \mathrm{~s}$ to reduce the effective time resolution and random noise. The movie plays at 100 averaged images per second. The PANSY radar's beam positions of local zenith, geographic north, east, south, and west are shown by an asterisk, a triangle, a square, the plus sign, and the cross sign, respectively.

Additional file 2: Figure A1. Footprints of the Arase satellite over the all-sky field of view of Syowa station on June 30, 2017. The IGRF model (black), T96 (magenta), and T04s (blue) models were used for the magnetic field tracing from the Arase satellite to an altitude of $100 \mathrm{~km}$. The field of view is shown for the emission height of $100 \mathrm{~km}$, with an elevation angle of $15^{\circ}$

Additional file 3: Figure A2. Ion production rate in the atmosphere over Syowa Station as obtained from the PHITS simulation, changing the electron spectral parameters of Gaussian width $W, k$, and $\gamma$ for models A, B, and $C$, respectively.
\end{abstract}

\section{Abbreviations}

HEP: High-energy electron experiments; HFA: High-frequency analyzer; PANSY: The Program of the Antarctic Syowa Mesosphere Stratosphere Troposphere Incoherent Scatter Radar; PHITS: Particle and heavy ion transport code system; XEP: Extremely high-energy electron experiment.

\section{Authors' contributions}

RK conducted the overall data analysis and prepared the manuscript. TN, YT, and AK provided their observational results of Syowa station. HAU, YE, and 
EKM helped the observation of high-speed imager at Syowa station. YT, MT, and KS helped the interpretation of PANSY data. YM, KS, SK, YK, MO, KH, SM, IS, TT, TH, NH, and TM helped the interpretation of Arase data. TS conducted PHITS simulation. All authors read and approved the final manuscript.

\section{Author details}

${ }^{1}$ National Institute of Polar Research, 10-3 Midori-cho, Tachikawa, Tokyo 190-8518, Japan. ${ }^{2}$ Joint Support-Center for Data Science Research, 10-3 Midori-cho, Tachikawa, Tokyo 190-0014, Japan. ${ }^{3}$ Research Institute for Sustainable Humanosphere, Kyoto University, Gokasho, Uji, Kyoto 611-0011, Japan. ${ }^{4}$ Department of Earth and Planetary Science, University of Tokyo, 7-3-1 Hongo, Bunkyo-ku, Tokyo 113-0033, Japan. ${ }^{5}$ Institute for Space-Earth Environmental Research, Nagoya University, Furo-cho, Chikusa-ku, Nagoya, Aichi 464-8601, Japan. ${ }^{6}$ Graduate School of Natural Science and Technology, Kanazawa University, Kakumamachi, Kanazawa, Ishikawa 920-1192, Japan.

${ }^{7}$ Department of Communication Engineering and Informatics, The University of Electro-Communications, 1-5-1 Chofugaoka, Chofu, Tokyo 182-8585, Japan. ${ }^{8}$ Institute of Space and Astronautical Science, Japan Aerospace Exploration Agency, 3-1-1 Yoshinodai, Chuo-ku, Sagamihara, Kanagawa 252-5210, Japan. 9 Japan Atomic Energy Agency, Shirakata 2-4, Tokai, Ibaraki 319-1195, Japan.

${ }^{10}$ Research and Development Directorate, Japan Aerospace Exploration Agency, Tsukuba 305-8505, Japan. ${ }^{11}$ Department of Polar Science, SOKENDAI, 10-3 Midori-cho, Tachikawa, Tokyo 190-8518, Japan.

\section{Acknowledgements}

RK thanks Y. Hirasima and H. Yamagishi for the discussions about auroral $X$-rays. The authors thank M. Shoji and R. Nomura for their efforts to create the EMIC database of the Arase satellite. Gratitude is also due to F. Tsuchiya and A. Kumamoto for providing the electron density data of the Arase satellite. PANSY is a multi-institutional project with a core comprising the University of Tokyo and National Institute of Polar Research. The PANSY radar is operated by the Japanese Antarctic Research Expedition (JARE). Observations at Syowa Station were carried out by JARE- 58 . The authors are also grateful all the members of JARE-58. The preparation of this paper was supported by an NIPR publication subsidy.

\section{Competing interests}

The authors declare that they have no competing interests.

\section{Availability of data and materials}

The present study used the PWE/HFA data of V03, PWE/OFA-SPEC L2 data v01.01, MGF-L2-v01.00, and XEP L2-omniflux v00_00. HEP L2-omniflux v01_02. Science data of the ERG (Arase) satellite were obtained from the ERG Science Center operated by ISAS/JAXA and ISEE/Nagoya University (http://ergsc.isee. nagoya-u.ac.jp/). The Arase satellite data will be publicly available via ERG Science Center on a project-agreed schedule. The PANSY radar observation data are available upon request (contact: Kaoru Sato). These data were downloaded and analyzed using the SPEDAS software (http://spedas.org) with the IUGONET and ERG plugins. The redistribution of the ground-based observational data has been supported by the IUGONET (Inter-university Upper atmosphere Global Observation NETwork) project (http://www.iugonet.org/).

\section{Consent for publication}

Not applicable.

Ethics approval and consent to participate

Not applicable.

\section{Funding}

RK and YM are supported by JSPS-Kakenhi (15H05815). RK, KS, MO, and YM are supported by JSPS-Kakenhi (16H06286). RK, AK, and YT are supported by JSPS-Kakenhi (15H02628). YK is supported by JSPS-Kakenhi (16H04056). SM is supported by JSPS-Kakenhi (14J02108). IS is supported by JSPS-Kakenhi (17H06140). KH and YM are supported by JSPS-Kakenhi (15H05747).

\section{Publisher's Note}

Springer Nature remains neutral with regard to jurisdictional claims in published maps and institutional affiliations.
Received: 21 August 2018 Accepted: 11 January 2019

Published online: 23 January 2019

\section{References}

Aggarwal KM, Nath N, Setty CSGK (1979) Collision frequency and transport properties of electrons in the ionosphere. Planet Space Sci 27:753-768

Aminaei A, Honary F, Kavanagh AJ, Spanswick E, Viljanen A (2006) Characteristics of night-time absorption spike events. Ann Geophys 24:1887-1904. https://doi.org/10.5194/angeo-24-1887-2006

Baker DN, Stauning P, Hones EW Jr, Higbie PR, Belian RD (1981) Near-equatorial, high-resolution measurements of electron precipitation at L 6.6. J Geophys Res 86(A4):2295-2313

Berger MJ, Seltzer SM (1972) Bremsstrahlung in the atmosphere. J Atmos Terr Phys 34:85-108

Brattli A, Blix TA, Lie-Svendsen O, Hoppe U-P, Lübken F-J, Rapp M, Singer W, Friedrich M (2006) Rocket measurements of positive ions during polar mesospheric winter echoes. Atmos Chem Phys 6:5515-5524

Brown NB, Davis TN, Hallinan TJ, Stenbaek-Nielsen HC (1976) Altitude of pulsating aurora determined by a new instrumental technique. Geophys Res Lett 3:403-404. https://doi.org/10.1029/GL003i007p00403

Codrescu MV, Fuller-Rowell TJ, Roble R, Evans DS (1997) Medium energy particle precipitation influences on the mesosphere and lower thermosphere. J Geophys Res 102(A):19977-19988. https://doi.org/10.1029/97ja01728

Czechowsky P, Reid IM, Rüster R, Schmidt G (1989) VHF radar echoes observed in the summer and winter polar mesosphere over Andoya, Norway. J Geophys Res 94(D4):5199-5217. https://doi.org/10.1029/JD094iD04p 05199

Daae M, Espy P, Nesse Tyssoy H, Newnham D, Stadsnes J, Soraas F (2012) The effect of energetic electron precipitation on middle mesospheric nighttime ozone during and after a moderate geomagnetic storm. Geophys Res Lett 39:L21811. https://doi.org/10.1029/2012GL053787

Frahm RA, Winningham JD, Sharber JR, Link R, Crowley G, Gaines EE, Chenette DL, Anderson BJ, Potemra TA (1997) The diffuse aurora: a significant source of ionization in the middle atmosphere. J Geophys Res 102(D23):28203-28214

Friedrich M, Torkar KM, Steiner RJ (2004) Empirical recombination rates in the lower ionosphere. Adv Space Res 34:1937-1942

Gledhill JA (1986) The effective recombination coefficient of electrons in the ionosphere between 50 and $150 \mathrm{~km}$. Radio Sci 21(3):399-408

Hargreaves JK, Browne S, Ranta H, Ranta A, Rosenberg TJ, Detrick DL (1997) A study of substorm-associated nightside spike events in auroral absorption using imaging riometers at South Pole and Kilpisjarvi. J Atmos Sol Terr Phys 59(8):853-872. https://doi.org/10.1016/S1364-6826(96)00061-2

Hedin AE (1991) Extension of the MSIS thermosphere model into the middle and lower atmosphere. J Geophys Res 96:1159-1172

Higashio N, Takashima T, Shinohara I, Matsumoto H (2018) The extremely highenergy electron experiment (XEP) onboard the Arase (ERG) satellite. Earth Planets Space 70:134. https://doi.org/10.1186/s40623-018-0901-X

Hirayama H, Namito Y, Bielajew AF, Wilderman SJ, Nelson WR (2005) The EGS5 code system, SLAC-R-730 and KEK report 2005-8. SLAC National Accelerator Laboratory and High Energy Accelerator Research Organization, Tsukuba

Horne RB, Thorne RM (2003) Relativistic electron acceleration and precipitation during resonant interactions with whistler-mode chorus. Geophys Res Lett 30:1527. https://doi.org/10.1029/2003GL016973,10

Isono Y, Mizuno A, Nagahama T, Miyoshi Y, Nakamura T, Kataoka R, Tsutsumi M, Ejiri K, Fujiwara H, Maezawa $H$ (2014) Variations of nitric oxide in the mesosphere and lower thermosphere over Antarctica associated with a magnetic storm in April 2012. Geophys Res Lett 41(7):2568

Kasaba Y, Ishisaka K, Kasahara Y, Imachi T, Yagitani S, Kojima H, Matsuda S, Shoji M, Kurita S, Hori T, Shinbori A, Teramoto M, Miyoshi Y, Nakagawa T, Takahashi N, Nishimura Y, Matsuoka A, Kumamoto A, Tsuchiya F, Nomura R (2017) Wire probe antenna (WPT) and Electric field detector (EFD) of plasma wave experiment (PWE) aboard Arase: specifications and initial evaluation results. Earth Planets Space. https://doi.org/10.1186/s4062 3-017-0760-X

Kasahara Y, Kasaba Y, Kojima H, Yagitani S, Ishisaka K, Kumamoto A, Tsuchiya F, Ozaki M, Matsuda S, Imachi T, Miyoshi Y, Hikishima M, Katoh Y, Ota M, Shoji M, Matsuoka A, Shinohara I (2018) The plasma wave experiment 
(PWE) on board the Arase (ERG) satellite. Earth Planets Space. https://doi. org/10.1186/s40623-018-0842-4

Kirkwood S (2007) Polar mesosphere winter echoes: a review of recent results. Adv Space Res 40:751-757. https://doi.org/10.1016/j.asr.2007.01.024

Kirkwood S, Osepian A, Belova E, Lee Y-S (2015) High-speed solar wind streams and polar mesosphere winter echoes at Troll, Antarctica. Ann Geophys 33:609-622. https://doi.org/10.5194/angeo-33-609-2015

Kremser G et al (1982) Coordinated balloon-satellite observations of energetic particles at the onset of a magnetospheric substorm. J Geophys Res 87(A6):4445-4453

Kremser G, Korth A, Ullaland SL, Perraut S, Roux A, Pedersen A, Schmidt R, Taskanen P (1988) Field-aligned beams of energetic electrons $(16 \mathrm{keV}<\mathrm{E}<80 \mathrm{keV}$ ) observed at geosynchronous orbit at substorm onsets. J Geophys Res 93(A12):14453-14464

Kumamoto A, Tsuchiya F, Kasahara Y, Kasaba Y, Kojima H, Yagitani S, Ishisaka K, Imachi T, Ozaki M, Matsuda S, Shoji M, Matsuoka A, Katoh Y, Miyoshi Y, Obara T (2018) High frequency analyzer (HFA) of plasma wave experiment (PWE) onboard the Arase spacecraft. Earth Planets Space. https:// doi.org/10.1186/s40623-018-0854-0

Lübken F-J, Strelnikov B, Rapp M, Singer W, Latteck R, Brattli A et al (2006) The thermal and dynamical state of the atmosphere 41 during pola mesosphere winter echoes. Atmos Chem Phys 6:13-24. https://doi. org/10.5194/acp-6-13-2006

Lübken F-J, Singer W, Latteck R, Strelnikova I (2007) Radar measurements of turbulence, electron densities, and absolute reflectivities during polar mesosphere winter echoes (PMWE). Adv Space Res 40:758-764

Luhmann JG (1977) Auroral bremsstrahlung spectra in the atmosphere. Atmos Terr Phys 39:595-600

Matsuda S, Kasahara Y, Kojima H, Kasaba Y, Yagitani S, Ozaki M, Imachi T, Ishisaka K, Kumamoto A, Tsuchiya F, Ota M, Kurita S, Miyoshi Y, Hikishima M, Matsuoka A, Shinohara I (2018) Onboard software of plasma wave experiment aboard Arase: instrument management and signal processing of waveform capture/onboard frequency analyzer. Earth Planets Space. https://doi.org/10.1186/s40623-018-0838-0

Mende SB, Frey HU, Morsony BJ, Immel TJ (2003) Statistical behavior of proton and electron auroras during substorms. J Geophys Res 108(A9):1339. https://doi.org/10.1029/2002JA009751

Meredith NP, Horne RB, Sicard-Piet A, Boscher D, Yearby KH, Li W, Thorne RM (2012) Global model of lower band and upper band chorus from multiple satellite observations. J Geophys Res 117:A10225. https://doi. org/10.1029/2012JA017978

Mitani T, Takashima T, Kasahara S, Miyake W, Hirahara M (2018) High-energy electron experiments (HEP) aboard the ERG (Arase) satellite. Earth Planets Space 70:77. https://doi.org/10.1186/s40623-018-0853-1

Miyoshi Y, Sakaguchi K, Shiokawa K, Evans D, Albert J, Connors M, Jordanova V (2008) Precipitation of radiation belt electrons by EMIC waves, observed from ground and space. Geophys Res Lett 35:L23101. https://doi. org/10.1029/2008GL035727

Miyoshi Y, Oyama S, Saito S, Kurita S, Fujiwara H, Kataoka R, Ebihara Y, Kletzing C, Reeves G, Santolik O, Clilverd M, Rodger CJ, Turunen E, Tsuchiya F (2015) Energetic electron precipitation associated with pulsating aurora: EISCAT and Van Allen Probe observations. J Geophys Res Space Phys 120:2754-2766. https://doi.org/10.1002/2014JA020690

Miyoshi Y, Shinohara I, Takashima T, Asamura K, Higashio H, Mitani T, Kasahara S, Yokota S, Kazama Y, Wang S-Y, Tam S, Ho P, Kasahara Y, Kasaba Y, Yagitani S, Matsuoka A, Kojima H, Katoh Y, Shiokawa K, Seki K (2018) Geospace exploration project ERG. Earth Planets Space. https://doi.org/10.1186/ s40623-018-0862-0

Newell PT, Sotirelis T, Wing S (2009) Diffuse, monoenergetic, and broadband aurora: the global precipitation budget. J Geophys Res 114:A09207. https ://doi.org/10.1029/2009JA014326

Nielsen E, Axford WI (1977) Small scale auroral absorption events associated with substorms. Nature 267:502-504
Nishiyama T, Sato K, Nakamura T, Tsutsumi M, Sato T, Kohma M, Nishimura K, Tomikawa Y, Ejiri MK, Tsuda TT (2015) Height and time characteristics of seasonal and diurnal variations in PMWE based on 1-year observations by the PANSY radar (69.0 $\left.0^{\circ} \mathrm{S}, 39.6^{\circ} \mathrm{E}\right)$. Geophys Res Lett 42:2100-2108. https:// doi.org/10.1002/2015GL063349

Nishiyama T, Sato K, Nakamura T, Tsutsumi M, Sato T, Tanaka Y, Nishimura K, Tomikawa Y, Kohma M (2018) Simultaneous observations of polar mesosphere winter echoes and cosmic noise absorptions in a common volume by the PANSY radar $\left(69.0^{\circ} \mathrm{S}, 39.6^{\circ} \mathrm{E}\right)$. J Geophys Res Space Phys. https://doi.org/10.1029/2017JA024717

Ono T (1993) Derivation of energy parameters of precipitating auroral electrons by using the intensity ratios of auroral emissions. J Geomagn Geoelectr 45(6):455-472

Ono T, Morishima K (1994) Energy parameters of precipitating auroral electrons obtained by using photometric observations. Geophys Res Lett 21(4):261-264

Oyama S, Kero A, Rodger CJ, Clilverd MA, Miyoshi Y, Partamies N, Turunen E, Raita T, Verronen PT, Saito S (2017) Energetic electron precipitation and auroral morphology at the substorm recovery phase. J Geophys Res Space Phys. https://doi.org/10.1002/2016ja023484

Ozaki M, Yagitani S, Kasahara Y, Kojima H, Kasaba Y, Kumamoto A, Tsuchiya F, Matsuda S, Matsuoka A, Sasaki T, Yumoto T (2018) Magnetic search coil (MSC) of plasma wave experiment (PWE) aboard the Arase (ERG) satellite. Earth Planets Space. https://doi.org/10.1186/s40623-018-0837-1

Parthasarathy R, Berkey FT (1965) Auroral zone studies of sudden-onset radiowave absorption events using multiple-station and multiple-frequency data. J Geophys Res 70(1):89-98

Rees MH (1964) Ionization in the Earth's atmosphere by aurorally associated Bremsstrahlung X-rays. Planet Space Sci 12(11):1093-1108

Sandahl I, Eliasson L, Lundin R (1980) Rocket observations of precipitating electrons over a pulsating aurora. Geophys Res Lett 7:309-312. https:// doi.org/10.1029/GL007i005p00309

Sato K, Tsutsumi M, Sato T, Nakamura T, Saito A, Tomikawa Y, Nishimura K, Kohma M, Yamagishi H, Yamanouchi T (2014) Program of the Antarctic Syowa MST/IS radar (PANSY). J Atmos Sol Terr Phys 118(Part A):2-15. https ://doi.org/10.1016/j.jastp.2013.08.022

Sato T, Iwamoto Y, Hashimoto S, Ogawa T, Furuta T, Abe S-I, Kai T, Tsai P-E, Matsuda N, Iwase H, Shigyo N, Sihver L, Niita K (2018) Features of particle and heavy ion transport code system (PHITS) version 3.02. J Nucl Sci Technol 55:684-690

Seppala A, Clilverd MA, Beharrell MJ, Rodger CJ, Verronen PT, Andersson ME, Newnham DA (2015) Substorm-induced energetic electron precipitation: impact on atmospheric chemistry. Geophys Res Lett 42:8172-8176. https ://doi.org/10.1002/2015GL065523

Spanswick E, Donovan E, Liu W, Wallis D, Aasnes A, Hiebert T, Jackel B, Henderson M, Frey H (2006) Substorm associated spikes in high energy particle precipitation. In: Pulkkinen TI, Tsyganenko NA, Friedel RHW (eds) The inner magnetosphere: physics and modeling, vol 155. Geophysical monograph series. American Geophysical Union, Washington. https://doi org/10.1029/155gm24

Strickland DJ, Daniell RE Jr, Jasperse JR, Basu B (1993) Transport-theoretic model for the electron-proton-hydrogen atom aurora 2. Model results. J Geophys Res 98(A12):21533-21548

Tomikawa Y (2017) Response of the middle atmosphere in the southern hemisphere to energetic particle precipitation in the latest reanalysis data. SOLA 13A:1-7. https://doi.org/10.2151/sola.13A-001

Tsyganenko NA (1996) Effects of the solar wind conditions on the global magnetospheric configuration as deduced from data-based field models. In: ESA SP-389. European Space Agency Publication, Paris, p 181

Tsyganenko NA, Sitnov MI (2005) Modeling the dynamics of the inner magnetosphere during strong geomagnetic storms. J Geophys Res 110:A03208. https://doi.org/10.1029/2004JA010798 